OPEN ACCESS

Edited by:

Maxwell Ware

Colorado State University,

United States

Reviewed by:

Gretchen Kroh,

Texas A\&M University, United States

Sam Wilson,

Queen Mary University of London,

United Kingdom

*Correspondence:

Guimin Xia

xiagm1229@126.com

Tieliang Wang

tieliangwang@syau.edu.cn

Specialty section:

This article was submitted to

Crop and Product Physiology, a section of the journal

Frontiers in Plant Science

Received: 07 January 2021 Accepted: 03 May 2021

Published: 31 May 2021

Citation:

Wang S, Zheng J, Wang Y, Yang $Q$, Chen $T$, Chen Y, Chi D, Xia G,

Siddique KHM and Wang T (2021)

Photosynthesis, Chlorophyll

Fluorescence, and Yield of Peanut

in Response to Biochar Application.

Front. Plant Sci. 12:650432.

doi: $10.3389 / \mathrm{fp} / \mathrm{s} .2021 .650432$

\section{Photosynthesis, Chlorophyll Fluorescence, and Yield of Peanut in Response to Biochar Application}

\author{
Shujun Wang ${ }^{1}$, Junlin Zheng', Yujia Wang ${ }^{1}$, Qingfeng Yang ${ }^{1}$, Taotao Chen', \\ Yinglong Chen ${ }^{2,3}$, Daocai Chi ${ }^{1}$, Guimin Xia ${ }^{1 *}$, Kadambot H.M. Siddique ${ }^{2,3}$ and \\ Tieliang Wang ${ }^{1 *}$
}

' Key Laboratory of Agricultural Soil and Water Engineering of Liaoning Province, College of Water Conservancy, Shenyang Agricultural University, Shenyang, China, ${ }^{2}$ The UWA Institute of Agriculture, The University of Western Australia, Perth, WA, Australia, ${ }^{3}$ School of Agriculture and Environment, The University of Western Australia, Perth, WA, Australia

The effect of biochar application on photosynthetic traits and yield in peanut (Arachis hypogaea L.) is not well understood. A 2-year field experiment was conducted in Northwest Liaoning, China to evaluate the effect of biochar application [0, 10, 20, and $40 \mathrm{t} \mathrm{ha}^{-1}$ (B0, B10, B20, and B40)] on leaf gas exchange parameters, chlorophyll fluorescence parameters, and yield of peanut. B10 improved photochemical quenching at flowering and pod set and reduced non-photochemical quenching at pod set, relative to B0. B10 and B20 increased actual photochemical efficiency and decreased regulated energy dissipated at pod set, relative to B0. B10 significantly increased net photosynthetic rate, transpiration rate, stomatal conductance, and water use efficiency at flowering and pod set, relative to BO. Compared with B0, B10 significantly improved peanut yield (14.6 and 13.7\%) and kernel yield (20.2 and 14.4\%). Biochar application increased leaf nitrogen content. B10 and B20 significantly increased plant nitrogen accumulation, as compared to B0. The net photosynthetic rate of peanut leaves had a linear correlation with plant nitrogen accumulation and peanut yield. The application of $10 \mathrm{t} \mathrm{ha}^{-1}$ biochar produced the highest peanut yield by enhancing leaf photosynthetic capacity, and is thus a promising strategy for peanut production in Northwest Liaoning, China.

Keywords: biochar, chlorophyll fluorescence, plant nitrogen accumulation, photosynthetic traits, peanut yield

\section{INTRODUCTION}

Peanut (Arachis hypogaea L.) is an annual legume crop. Global peanut consumption is increasing at a rate of around $3 \%$ per annum. China produces $40 \%$ of the world's peanuts (FAOSTAT, 2018). Liaoning Province, is one of the main areas for peanut production in China and the primary export base of high-quality peanut. The Northwest Liaoning is a competitive producing area for peanut with a typical characteristic of sand and wind in semi-arid regions of Northeast China. However, peanut production in this area is limited by poor soil water and nutrient holding capacities, and water deficiency (Bai et al., 2014). Hence, the incorporation of plastic film mulching and supplemental irrigation have been studied as an extremely effective strategy with potential for decreasing soil evaporation, and enhancing crop growth, yield, and water use efficiency 
(Li and Gong, 2002; Ali et al., 2018; Xia et al., 2021a). However, the enhanced productivity under plastic mulches has been reported to result in lower soil fertility, which limit the subsequent crop productivity (Li et al., 2007; Steinmetz et al., 2016).

Biochar is produced through pyrolysis of biomass under limited oxygen environment (Lehmann et al., 2011). Generally, biochar with larger specific surface area, pore structure, abundant surface functional groups, and nutrient characteristics (e.g., C, N, $\mathrm{P}, \mathrm{K}, \mathrm{S}, \mathrm{Ca}$, and $\mathrm{Mg}$ ) could improve soil sustainability (Ippolito et al., 2020; Leng et al., 2020; Ye et al., 2020). Most studies have shown that biochar is an effective agricultural practice for improving water and soil conditions in farmland and increasing crop yield and fertilizer use efficiency due to its unique structure (Clough et al., 2013; Laghari et al., 2015; Haider et al., 2017; Lin et al., 2017). The porous physical structure of biochar induces a sorption capacity to inorganic nitrogen and can potentially allow the slow release of nutrients to improve plant growth (Novak et al., 2012; El-Naggar et al., 2019). Biochar impacts the soil nitrogen, and is expected to enhance leaf nitrogen and photosynthesis (Kammann et al., 2011; Ali et al., 2020). Biochar addition to soil has positive effect on photosynthesis, being an important process that affects crop yield. When biochar application improves nitrogen accumulation, it also helps to increase leaf nitrogen content and therefore increases photosynthesis (Nguyen et al., 2017; Ali et al., 2020). The photosynthetic rate was increased at $40 \mathrm{t} \mathrm{ha}^{-1}$ biochar addition, and this enhancement in the leaf photosynthetic rate was due to the increased nitrogen accumulation (Ali et al., 2020). Biochar amendment increased the effective photochemical quantum yield of PSII and decreased the fluorescence yield for heat dissipation, therefore improved $\mathrm{P}_{n}$ (Abideen et al., 2020).

Most studies on peanut photosynthesis have focused on photosynthetic rate changes at different growth stages (Xu et al., 2015; Sun et al., 2018; Liu et al., 2019). However, limited information is available on the biochar effect on chlorophyll fluorescence and gas exchange parameters of peanut, especially in situ in the field. Aims of our study were to evaluate the effects of biochar application on photosynthesis from the perspective of chlorophyll fluorescence parameters, leaf nitrogen content, and plant nitrogen accumulation. We hypothesized that: (1) biochar application would improve peanut yield via enhancing leaf photosynthetic traits; (2) biochar improves the photosynthetic rate due to increasing the proportion of open photosystem II reaction centers, and nitrogen accumulation at low application rates.

\section{MATERIALS AND METHODS}

\section{Experimental Sites and Materials}

The field experiment was carried out at the Scientific Observation Experimental Station in Fuxin $\left(42.11^{\circ} \mathrm{N}, 121.65^{\circ} \mathrm{E}\right)$, Liaoning Province, China, during the 2018 and 2019 growing seasons (May to October). This area with typical sand and wind conditions of semi-arid regions in Northeast China, has cold, dry winters and hot summers according to the Köppen-Geiger climate classification (Peel et al., 2007). Average annual rainfall is about $400 \mathrm{~mm}$ (60\% from June to August), with average annual evaporation greater than $1,800 \mathrm{~mm}$. Droughts are frequent. The daily weather data during the 2018 and 2019 peanut growing seasons are shown in Figure 1. The soil texture was sandy loam with $\mathrm{pH}$ 5.96, $1.44 \mathrm{~g} \mathrm{~cm}^{-3}$ bulk density, $19.5 \%$ (w/w) field capacity (FC), $0.62 \mathrm{~g} \mathrm{~kg}^{-1}$ total nitrogen, $142 \mathrm{mg} \mathrm{kg}^{-1}$ available potassium, and $18.1 \mathrm{mg} \mathrm{kg}^{-1}$ available phosphorus. The biochar was derived from maize straw pyrolyzed at $600^{\circ} \mathrm{C}$ with $\mathrm{pH} 8.14$, $18.9 \%$, carbon content, $0.58 \%$ nitrogen content, $4.76 \mathrm{~g} \mathrm{~kg}^{-1}$ available potassium, and $0.33 \mathrm{~g} \mathrm{~kg}^{-1}$ available phosphorus.

\section{Experimental Design, Establishment and Maintenance}

The experiment was a randomized complete block design comprising four biochar application rates $(0,10,20$, and $40 \mathrm{t}$ $\mathrm{ha}^{-1}$; B0, B10, B20, and B40) and three replicates (plots). Supplemental irrigation via a plastic mulched drip system was applied during the flowering and pod setting stages when peanut growth is more sensitive to water deficit than other stages. The field was irrigated up to $90 \%$ FC when the soil moisture content dropped to $\leq 55 \%$ FC. The biochar was fully mixed with the upper $0-20 \mathrm{~cm}$ soil layer by rotary before sowing in 2018 . No additional biochar was applied in the second year. Basal fertilizers were applied at the rate of $50 \mathrm{~kg} \mathrm{ha}^{-1} \mathrm{~N}, 170 \mathrm{~kg} \mathrm{ha}^{-1} \mathrm{P}_{2} \mathrm{O}_{5}$, and $156 \mathrm{~kg}$ $\mathrm{ha}^{-1} \mathrm{~K}_{2} \mathrm{O}$.

Peanut cultivar Baisha 1016 origing in Guangdong Province was sown on 16 May 2018 and 19 May 2019 and harvested on 21 September 2018 and 23 September 2019. A trapezoidal ridge with a width of $0.7 \mathrm{~m}$ was formed by plough. Two rows were sown on the ridge of each hill $\left(167,000\right.$ hills $\left.\mathrm{ha}^{-1}\right)$. The ridges were covered with white plastic film $(0.008 \mathrm{~mm}$ thick $)$ immediately after sowing. Each plot was $1 \times 7.5 \mathrm{~m}^{2}$. Groundwater was used, with the irrigation amount determined by monitoring the volumetric water meter equipped in each plot. Other field management, including weeds, insects, and diseases control, were in line with local farmer practices.

\section{Sampling and Measurements Chlorophyll Fluorescence Parameters}

Chlorophyll fluorescence parameters of peanut were measured using the LI-6800 (LI-COR, Lincoln, NE, United States) photosynthesis measurement system with multiphase flash fluorescence (6800-01) at flowering (19 July 2018 and 16 July 2019) and pod set (8 August 2018 and 9 August 2019) on clear and cloudless days. To avoid influence of the changes in $\mathrm{CO}_{2}$ concentration in the air, the $\mathrm{CO}_{2}$ inlet of the instrument was connected to a $\mathrm{CO}_{2}$ cartridge $\left(400 \mu \mathrm{mol} \mathrm{mol}{ }^{-1}\right)$. The third fully expanded leaf on the main stem were wrapped in aluminum foil. After remaining in complete darkness overnight, we measured minimal fluorescence yield $\left(\mathrm{F}_{o}\right)$ using a measuring light $\left(0.005 \mu \mathrm{mol} \mathrm{m}^{-2} \mathrm{~s}^{-1}\right)$. Maximal fluorescence yield $\left(\mathrm{F}_{m}\right)$ was measured using a $1 \mathrm{~s}$ saturating pulse at $8,000 \mu \mathrm{mol} \mathrm{m} \mathrm{m}^{-2} \mathrm{~s}^{-1}$ in dark-adapted leaves. The leaves were continuously illuminated for $20 \mathrm{~min}$ with an actinic light $\left(1,400 \mu \mathrm{mol} \mathrm{m}^{-2} \mathrm{~s}^{-1}\right)$ to record the steady-state yield of fluorescence $\left(\mathrm{F}_{s}\right)$. Maximal light-adapted 

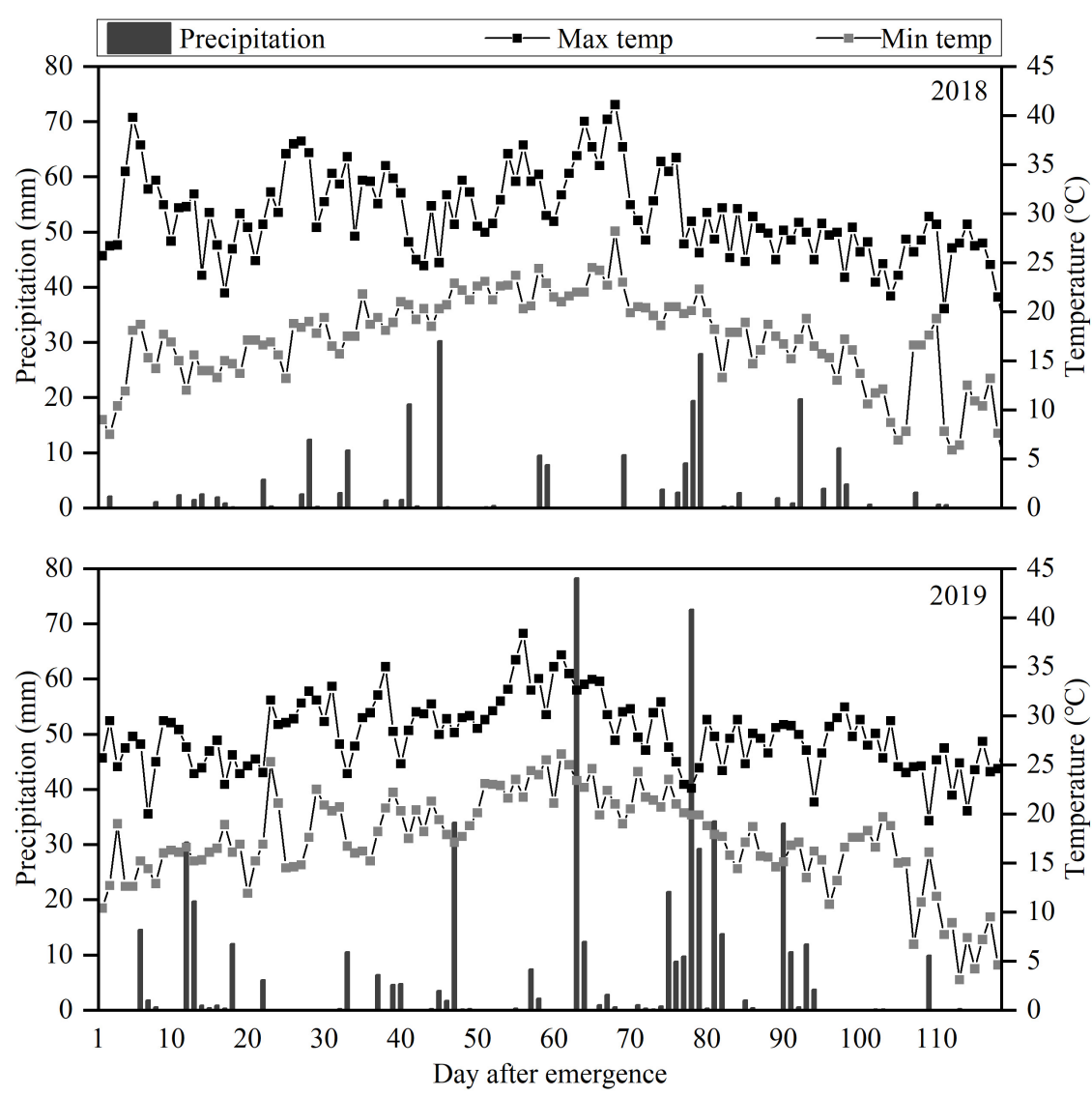

FIGURE 1 | Daily precipitation and maximum (Max) and minimum (Min) temperatures during the 2018 and 2019 peanut growing seasons.

fluorescence yield $\left(\mathrm{F}_{m}{ }^{\prime}\right)$ was determined by $8,000 \mu \mathrm{mol} \mathrm{m} \mathrm{m}^{-2}$ $\mathrm{s}^{-1}$. The actinic light was turned off, and minimal fluorescence yield $\left(\mathrm{F}_{o}{ }^{\prime}\right)$ in light-adapted state was determined after $5 \mathrm{~s}$ of farred illumination. The difference between the measured values of $\mathrm{F}_{m}$ and $\mathrm{F}_{o}$ is the variable fluorescence $\left(\mathrm{F}_{v}\right)$. The chlorophyll fluorescence parameters were calculated using the following formulas (Kooten and Snel, 1990; Maxwell and Johnson, 2000; Kramer et al., 2004):

$$
\begin{gathered}
\mathrm{Fv} / \mathrm{Fm}=(\mathrm{Fm}-\mathrm{Fo}) / \mathrm{Fm} \\
\Phi P S I I=\left(\mathrm{Fm}^{\prime}-\mathrm{Fs}\right) / \mathrm{Fm}^{\prime} \\
\Phi \mathrm{NPQ}=\mathrm{Fs} / \mathrm{Fm}^{\prime}-\mathrm{Fs} / \mathrm{Fm} \\
\Phi \mathrm{NO}=\mathrm{Fs} / \mathrm{Fm} \\
\mathrm{qP}=\left(\mathrm{Fm}^{\prime}-\mathrm{Fs}\right) /\left(\mathrm{Fm}^{\prime}-\mathrm{Fo}^{\prime}\right) \\
\mathrm{NPQ}=\mathrm{Fm} / \mathrm{Fm}^{\prime}-1
\end{gathered}
$$

where $\mathrm{F}_{v} / \mathrm{F}_{m}$ is maximal photochemical efficiency of photosystem II (PSII), $\Phi_{P S I I}$ is actual photochemical efficiency of PSII, $\Phi_{N P Q}$ is quantum yield for energy dissipated via $\Delta \mathrm{pH}$ and xanthophyllregulated processes, $\Phi_{N O}$ is quantum yield of non-regulated energy dissipated in PSII, and $\mathrm{qP}$ and NPQ are photochemical and non-photochemical quenching, respectively.

\section{Gas Exchange Parameters, Leaf Nitrogen Content and Plant Nitrogen Accumulation}

Gas exchange parameters were measured on the same dates and same leaves as those for chlorophyll fluorescence parameters measurements. Net photosynthesis rate $\left(\mathrm{P}_{n}\right)$, transpiration rate $\left(\mathrm{T}_{r}\right)$, stomatal conductance $\left(\mathrm{G}_{s}\right)$, intercellular $\mathrm{CO}_{2}$ concentration $\left(\mathrm{C}_{i}\right)$, and ambient $\mathrm{CO}_{2}$ concentration $\left(\mathrm{C}_{a}\right)$ were measured with LI-6800 (LI-COR, Lincoln, NE, United States) photosynthesis measurement system. The stomatal limitation value $\left(\mathrm{L}_{s}\right)$ was calculated as $1-\mathrm{C}_{i} / \mathrm{C}_{a}$, and WUE was calculated as $\mathrm{P}_{n} / \mathrm{T}_{r}$ (Fang et al., 2018).

After the determination of gas exchange parameters, the third fully expanded leaf on the main stem of 20 plants in each pot was collected. Plant samples were collected at flowering and pod set, and were separated into various parts: roots, stems, leaves, and pods. All the samples were oven-dried at $105^{\circ} \mathrm{C}$ for $30 \mathrm{~min}$ and then at $80^{\circ} \mathrm{C}$ to constant weight. After 
weighing, these samples were ground into powder for measuring nitrogen content. The full-automatic KjelFlex K-360 analyzer (BUCHIK, Switzerland) was used to determine nitrogen content. Plant nitrogen accumulation was calculated by multiplying total nitrogen concentration in roots, stems, leaves, and pods with respective dry matter at flowering and pod set stages.

\section{Yield and Yield Components}

Peanuts were harvested from $1 \mathrm{~m}^{2}$ in the center of each plot. The pods were air-dried for about 1 week before being measured for peanut yield, kernel yield, 100-pod weight, and 100-kernel weight (Tan et al., 2018). The shelling percentage was calculated as (kernel weight/pod weight) $\times 100 \%$ (Luo et al., 2017).

\section{Statistical Analysis}

SPSS 19.0 statistic software (SPSS Inc., Chicago, IL, United States) was used to perform the statistical analysis. Year and biochar application were assumed to be fixed factor and the replicates were assumed to be random factors. Error bars in the figures represent standard errors of the mean. Least significant differences were used to separate treatment means at the $5 \%$ probability level. Regression analysis was used to evaluate the relationships between leaf nitrogen content and net photosynthetic rate, net photosynthetic rate and peanut yield. The responses of chlorophyll fluorescence parameters, gas exchange parameters, leaf nitrogen content, yield, and yield components to biochar application were further analyzed with the principal component analysis in $\mathrm{R}$ studio version 1.1.442 using the Factoextra package (Kassambara, 2015).

\section{RESULTS}

\section{Chlorophyll Fluorescence Parameters}

Year, biochar application, and $\mathrm{Y} \times \mathrm{B}$ interaction had no significant effects on $\mathrm{F}_{v} / \mathrm{F}_{m}$ at flowering or pod set (Table 1 and Figures 2A,G). Biochar application had a significant effect on $\Phi_{P S I I}$ at flowering and pod set, but there were no significant differences for year or $\mathrm{Y} \times \mathrm{B}$ interaction (Table 1). B10 increased $\Phi_{P S I}$ at flowering by 7.1 in 2018 and $8.8 \%$ in 2019 , relative to B0 (Figure 2B). At pod set, B10 increased $\Phi_{P S I I}$ by 13.0 in 2018 and $14.9 \%$ in 2019, and B20 increased $\Phi_{P S I I}$ by 13.0 in 2018 and $12.8 \%$ in 2019 , relative to B0 (Figure $\mathbf{2 H}$ ). Among the four biochar treatments, B10 had the highest $\Phi_{P S I I}$ values at flowering and pod set each year.

Biochar application had a significant effect on $\Phi_{N P Q}$ at pod set but not at flowering (Table $\mathbf{1}$ and Figures $2 \mathrm{C}, \mathrm{I}$ ). Year and $\mathrm{Y} \times \mathrm{B}$ interaction had no significant effect on $\Phi_{N P Q}$ at flowering or pod set. There were no significant effects of biochar application, year, or $\mathrm{Y} \times \mathrm{B}$ interaction on $\Phi_{N O}$ at flowering or pod set (Table 1 and Figures 2D,J). At pod set, $\Phi_{N P Q}$ decreased with increasing biochar application rate to $\mathrm{B} 10$ and then increased. B10 and B20 decreased $\Phi_{N P Q}$ by 30.0 and $26.7 \%$ in 2018 , and 27.6 and $24.1 \%$ in 2019, respectively, as compared to B0.

Biochar application had a significant effect on $\mathrm{qP}$ at flowering and pod set, but there were no significant differences for year or $\mathrm{Y} \times \mathrm{B}$ interaction (Table 1). At flowering, B10 enhanced qP by 11.7 and $7.6 \%$ in 2018 and 2019, respectively, relative to B0 (Figure 2E). At pod set, B10, B20, and B40 enhanced $\mathrm{qP}$ by $8.7,7.2$, and $5.8 \%$ in 2018 , respectively, as compared to B0, but there were no significant differences between these treatments (Figure 2K). In 2019, B10 enhanced qP by $10.3 \%$, relative to B0. Biochar application had a significant effect on NPQ at pod set but not at flowering. No significant differences were observed for year or $\mathrm{Y} \times \mathrm{B}$ interaction of NPQ at flowering or pod set (Table 1 and Figure 2F). At pod set, B10 and B20 decreased NPQ by up to $31.1 \%$ in 2018 and B10 decreased NPQ by $27.4 \%$ in 2019 , as compared to B0 (Figure 2L).

\section{Gas Exchange Parameters and Leaf Nitrogen Content}

Biochar application had a significant effect on $\mathrm{P}_{n}$ at flowering and pod set, but there were no significant effects for year or $\mathrm{Y} \times \mathrm{B}$ interaction (Table 1). B10 increased $\mathrm{P}_{n}$ at flowering by $16.1 \%$ in 2018, relative to $\mathrm{B} 0$ (Figure $\mathbf{3 A}$ ). B10 and B20 increased $\mathrm{P}_{n}$ at

TABLE 1 | Leaf chlorophyll fluorescence parameters and gas exchange parameters at the flowering and pod set in peanut with four rates of biochar in the 2018 and 2019 growing seasons.

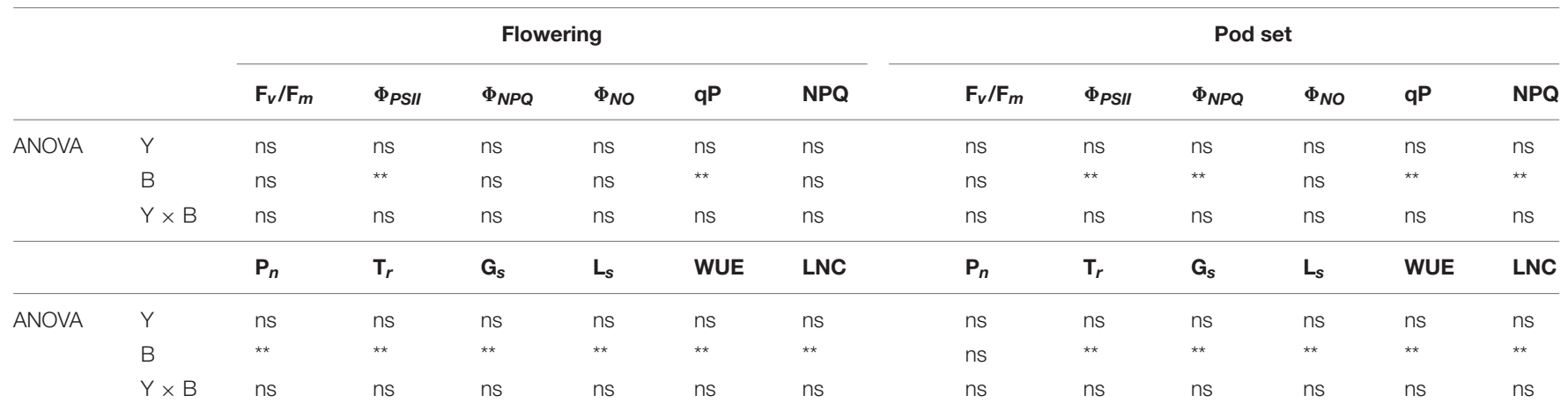

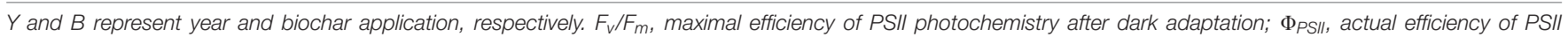

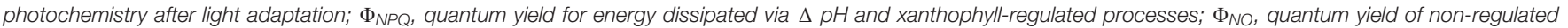

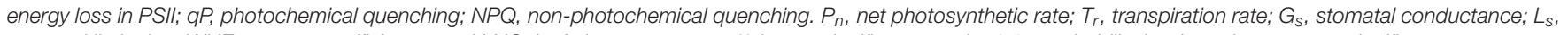
stomatal limitation; WUE, water-use efficiency; and LNC, leaf nitrogen content. ${ }^{* *}$ denote significance at the 0.01 probability level. ns denotes non-significance. 


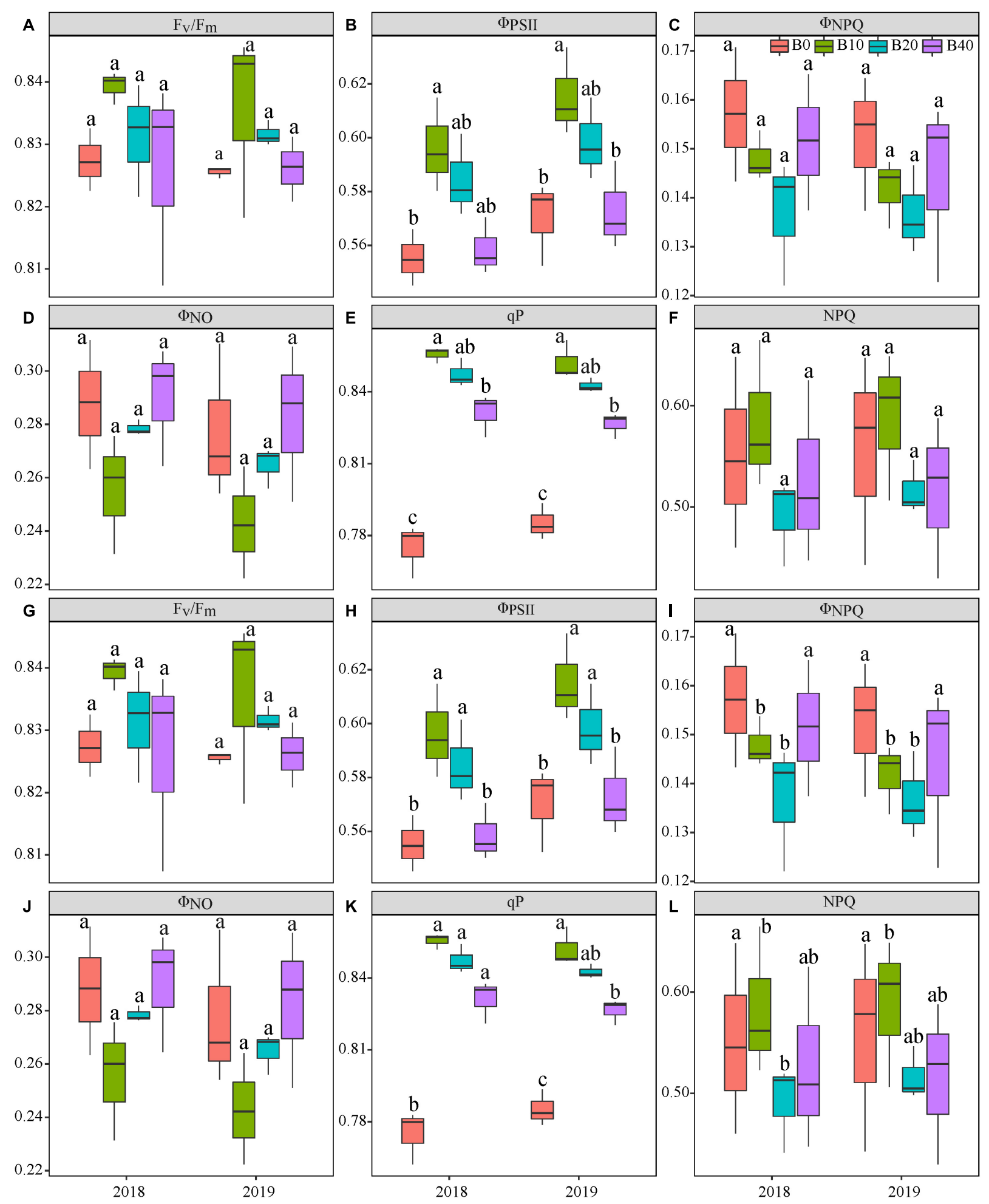

FIGURE 2 | Chlorophyll fluorescence parameters at the flowering (A-F) and pod set (G-L) in peanut with four rates of biochar in the 2018 and 2019 growing seasons. $F_{v} / F_{m}$, maximal efficiency of PSIl photochemistry after dark adaptation; $\Phi_{P S I}$, actual efficiency of PSIl photochemistry after light adaptation; $\Phi_{N P Q}$, quantum yield for energy dissipated via $\Delta \mathrm{pH}$ and xanthophyll-regulated processes; $\Phi_{N O}$, quantum yield of non-regulated energy loss in PSIl; qP, photochemical quenching; and NPQ, non-photochemical quenching. B0, B10, B20, and B40 represent biochar application rates at 0, 10, 20, and $40 \mathrm{t} \mathrm{ha}^{-1}$, respectively. For each parameter in each year, mean data with different letters denote significant difference among treatments at $P<0.05$. 


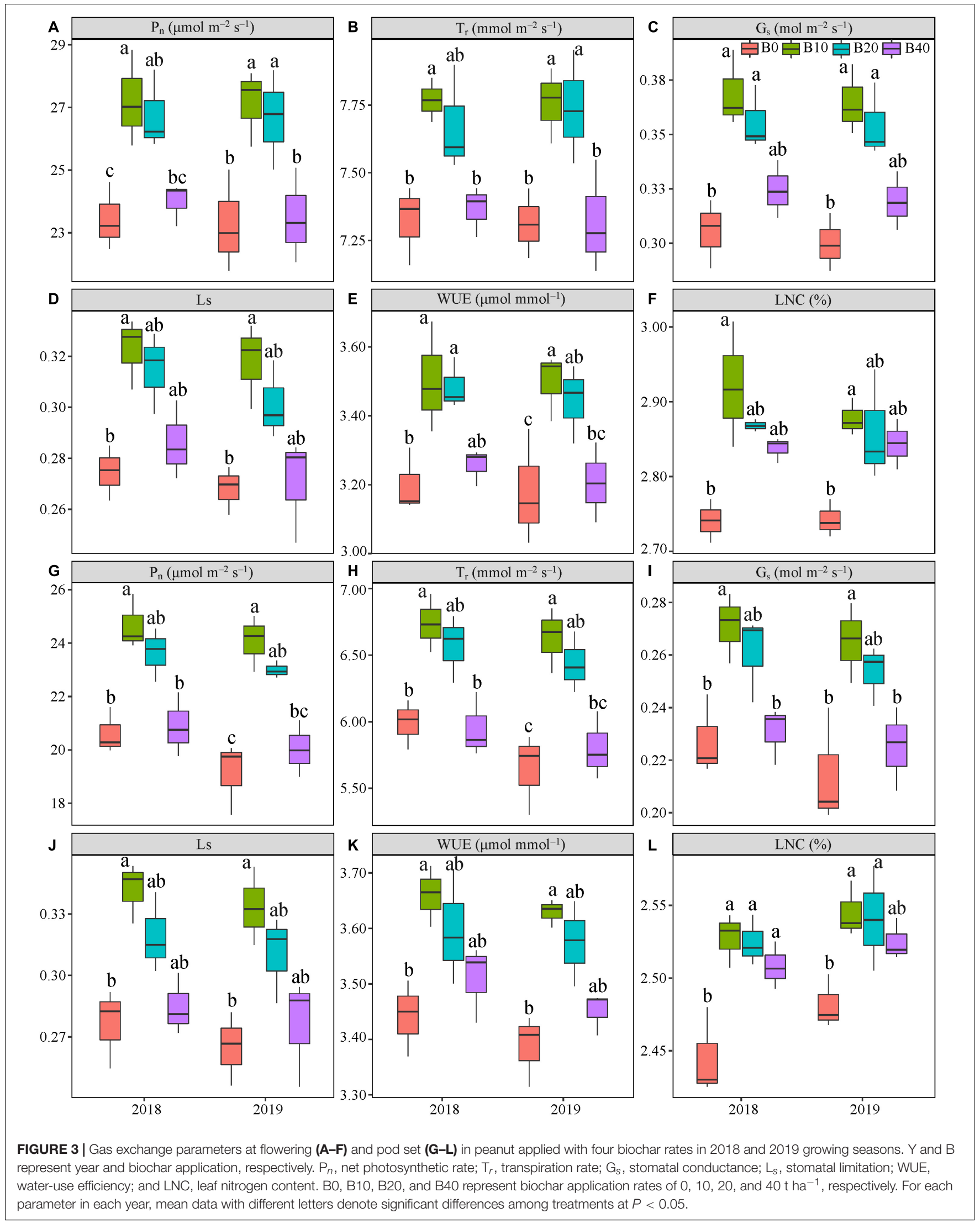


flowering by up to $16.7 \%$ in 2019 , as compared to B0. At pod set, $\mathrm{B} 10$ increased $\mathrm{P}_{n}$ by $19.6 \%$ in 2018 and $25.8 \%$ in 2019 , relative to $\mathrm{B} 0$ (Figure 3G). B10 had the highest $\mathrm{P}_{n}$ at flowering and pod set in both years.

Application of biochar had significant effect on $\mathrm{T}_{r}$ at flowering and pod set. There were no significant effects of year or $\mathrm{Y} \times \mathrm{B}$ interaction on $\mathrm{T}_{r}$ during these two stages (Table 1). Compared with B0, B10 increased $\mathrm{T}_{r}$ at flowering by $6.1 \%$ in 2018 . B10 and $\mathrm{B} 20$ increased $\mathrm{T}_{r}$ at flowering by up to $6.1 \%$ in 2019 , relative to B0 (Figure 3B). B10 increased $\mathrm{P}_{n}$ at pod set by $12.5 \%$ in 2018 and $17.5 \%$ in 2019 , relative to B0 (Figure $3 \mathbf{H}$ ). Among the four biochar treatments, $\mathrm{B} 10$ had the highest $\mathrm{T}_{r}$ at flowering and pod set in both years.

The $G_{s}$ was significantly affected by biochar application at both flowering and pod set stages. No significant differences in year or $\mathrm{Y} \times \mathrm{B}$ interaction of $\mathrm{G}_{s}$ were observed at both stages (Table 1). At flowering, B10 and B20 increased $\mathrm{G}_{s}$ by up to $20.8 \%$ in 2018 and $21.6 \%$ in 2019, relative to B0 (Figure 3C). $B 10$ increased $G_{s}$ at pod set by $19.2 \%$ in 2018 and $23.6 \%$ in 2019, as compared to B0 (Figure 3I). Among the four biochar treatments, B10 had the highest $\mathrm{G}_{s}$ at flowering and pod set in both years.

Application of biochar had a significant effect on $\mathrm{L}_{s}$ at flowering and pod set. There were no significant differences in year or $\mathrm{Y} \times \mathrm{B}$ interaction of $\mathrm{L}_{s}$ during these two stages (Table 1). Compared with $\mathrm{B} 0, \mathrm{~B} 10$ increased $\mathrm{L}_{s}$ at flowering by $17.5 \%$ in 2018 and $18.6 \%$ in 2019, and at pod set by $23.8 \%$ in 2018 and $25.8 \%$ in 2019 (Figures 3D,J). The highest value of $\mathrm{L}_{s}$ at flowering and pod set in both years were appeared in B10.

Biochar application significantly affected WUE at flowering and pod set, but there were no significant effects for year or $\mathrm{Y} \times \mathrm{B}$ interaction (Table 1). At flowering, B10 and B20 increased WUE by up to $9.4 \%$ in 2018, as compared to B0 (Figure 3E). B10 increased WUE by $10.0 \%$ in 2019 , as compared to B0. At pod set, B10 increased WUE by $6.3 \%$ in 2018 and $7.1 \%$ in 2019, relative to B0 (Figure 3K). B10 had the highest mean value of WUE at flowering and pod set in both years.

The LNC was significantly affected by biochar application at flowering and pod set. No significant differences in year or $\mathrm{Y} \times \mathrm{B}$ interaction were observed (Table 1). At flowering and pod set, with increasing biochar application rates, LNC increased to $\mathrm{B} 10$ and then decreased (Figures 3F,L). Among the four biochar treatments, B10 had the highest LNC at flowering and pod set in both years.

\section{Nitrogen Accumulation and Distribution}

The effects of biochar application on root, stem, leaf, and total nitrogen accumulation were significant at flowering, but there were no significant effects for year or $\mathrm{Y} \times \mathrm{B}$ interaction (Table 2). B10 and B20 improved total nitrogen accumulation by 22.5 and $18.6 \%$ in 2018, 24.6 and $23.6 \%$ in 2019, relative to B0. Compare with B0, B10 and B20 improved root nitrogen accumulation by up to $25.6 \%$ in 2018 and $30.8 \%$ in 2019 . The stem nitrogen accumulation in B10 improved by $21.6 \%$ in 2018, relative to $\mathrm{B} 0$. B10 and B20 improved stem nitrogen accumulation by up to $28.5 \%$ in 2019 , as compared to B0. B10 improved leaf nitrogen accumulation by $26.4 \%$ in 2018 and $29.0 \%$ in 2019 .

The root, stem, leaf, pod and total nitrogen accumulation were significantly affected by biochar application at pod set. No significant differences in year or $\mathrm{Y} \times \mathrm{B}$ interaction of root, stem, leaf, pod, and total nitrogen accumulation were observed at pod set (Table 3). The total nitrogen accumulation for B10 and B20 were higher than that of B0 by 25.0 and $15.3 \%$ in 2018, 23.7 and $20.3 \%$ in 2019, respectively, as compared to B0. B10 improved root nitrogen accumulation by $30.4 \%$ in 2018 , relative to $\mathrm{B} 0$. Compared with $\mathrm{B} 0, \mathrm{~B} 10$, and $\mathrm{B} 20$ improved root nitrogen accumulation by up to $30.0 \%$ in 2019 . The stem nitrogen accumulation for B10 was $21.0 \%$ in 2018 and $17.8 \%$ in 2019 higher than that of B0. B10 and B20 improved leaf nitrogen accumulation by up to $24.0 \%$ in 2018 and $24.3 \%$ in

TABLE 2 | Nitrogen accumulation and distribution at the flowering in peanut with four rates of biochar in the 2018 and 2019 growing seasons.

\begin{tabular}{|c|c|c|c|c|c|c|c|c|c|c|}
\hline \multirow[t]{2}{*}{ Year } & \multirow[t]{2}{*}{ Treatment } & \multirow[t]{2}{*}{ Total kg ha $\mathbf{~}^{-1}$} & \multicolumn{2}{|l|}{ Root } & \multicolumn{2}{|l|}{ Stem } & \multicolumn{2}{|l|}{ Leaf } & \multicolumn{2}{|l|}{ Pod } \\
\hline & & & kg ha $a^{-1}$ & $\%$ & $\mathrm{~kg} \mathrm{ha}^{-1}$ & $\%$ & $\mathrm{~kg} \mathrm{ha}^{-1}$ & $\%$ & $\mathrm{~kg} \mathrm{ha}^{-1}$ & $\%$ \\
\hline \multirow[t]{4}{*}{2018} & B0 & $64.9 \pm 5.12 b$ & $2.89 \pm 0.27 c$ & 4.47 & $18.5 \pm 1.10 \mathrm{~b}$ & 28.5 & $36.7 \pm 3.37 b$ & 56.5 & $6.84 \pm 0.74 a$ & 10.5 \\
\hline & B10 & $79.5 \pm 2.11 a$ & $3.63 \pm 0.28 a$ & 4.57 & $22.5 \pm 0.87 a$ & 28.4 & $46.4 \pm 2.36 a$ & 58.4 & $6.86 \pm 0.91 a$ & 8.65 \\
\hline & $\mathrm{B} 20$ & $77.0 \pm 1.75 a$ & $3.61 \pm 0.17 a$ & 4.69 & $21.9 \pm 1.81 \mathrm{ab}$ & 28.4 & $44.5 \pm 1.64 a b$ & 57.8 & $6.99 \pm 0.73 a$ & 9.09 \\
\hline & $\mathrm{B} 40$ & $70.4 \pm 2.94 \mathrm{ab}$ & $2.93 \pm 0.20 b$ & 4.16 & $20.7 \pm 1.12 \mathrm{ab}$ & 29.4 & $39.7 \pm 1.16 \mathrm{ab}$ & 56.5 & $7.00 \pm 0.92 a$ & 9.93 \\
\hline \multirow[t]{4}{*}{2019} & $\mathrm{BO}$ & $61.9 \pm 2.54 b$ & $2.73 \pm 0.26 b$ & 4.43 & $17.2 \pm 0.90 b$ & 27.8 & $35.2 \pm 1.56 c$ & 56.9 & $6.78 \pm 0.31 a$ & 11.0 \\
\hline & B10 & $77.1 \pm 6.54 a$ & $3.51 \pm 0.34 a$ & 4.56 & $21.4 \pm 1.56 a$ & 27.8 & $45.4 \pm 5.39 a$ & 58.8 & $6.81 \pm 0.64 a$ & 8.90 \\
\hline & B20 & $76.5 \pm 3.88 \mathrm{a}$ & $3.57 \pm 0.48 a$ & 4.68 & $22.1 \pm 1.64 a$ & 28.9 & $44.0 \pm 4.02 \mathrm{ab}$ & 57.5 & $6.82 \pm 0.70 \mathrm{a}$ & 8.95 \\
\hline & B40 & $69.4 \pm 1.05 a b$ & $3.02 \pm 0.27 b$ & 4.35 & $19.2 \pm 1.80 \mathrm{ab}$ & 27.6 & $40.4 \pm 1.44 a b c$ & 58.2 & $6.81 \pm 0.35 a$ & 9.82 \\
\hline \multicolumn{11}{|c|}{ ANOVA } \\
\hline Y & & ns & ns & & ns & & ns & & ns & \\
\hline$B$ & & $\star \star$ & $\star \star$ & & $\star \star$ & & $\star \star$ & & ns & \\
\hline$Y \times B$ & & ns & ns & & ns & & ns & & ns & \\
\hline
\end{tabular}

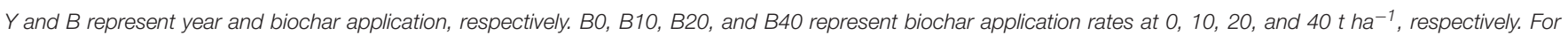

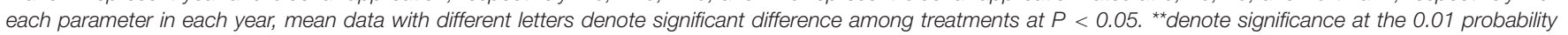
level. ns denotes non-significance. 
TABLE 3 | Nitrogen accumulation and distribution at the pod set in peanut with four rates of biochar in the 2018 and 2019 growing seasons.

\begin{tabular}{|c|c|c|c|c|c|c|c|c|c|c|}
\hline \multirow[t]{2}{*}{ Year } & \multirow[t]{2}{*}{ Treatment } & \multirow[t]{2}{*}{ Total kg ha ${ }^{-1}$} & \multicolumn{2}{|l|}{ Root } & \multicolumn{2}{|l|}{ Stem } & \multicolumn{2}{|l|}{ Leaf } & \multicolumn{2}{|l|}{ Pod } \\
\hline & & & $\mathbf{k g ~ h a} a^{-1}$ & $\%$ & $\mathrm{~kg} \mathrm{ha}^{-1}$ & $\%$ & $\mathrm{~kg} \mathrm{ha}^{-1}$ & $\%$ & kg ha ${ }^{-1}$ & $\%$ \\
\hline \multirow[t]{4}{*}{2018} & $\mathrm{BO}$ & $124 \pm 2.8 b$ & $3.16 \pm 0.28 b$ & 2.54 & $27.1 \pm 1.53 b$ & 21.8 & $36.6 \pm 1.72 b$ & 29.4 & $57.5 \pm 0.92 b$ & 46.2 \\
\hline & $\mathrm{B} 10$ & $155 \pm 7.6 \mathrm{a}$ & $4.12 \pm 0.25 a$ & 2.66 & $32.8 \pm 1.04 a$ & 21.1 & $45.4 \pm 2.40 a$ & 29.3 & $73.0 \pm 4.75 a$ & 47.0 \\
\hline & $\mathrm{B} 20$ & $143 \pm 8.3 a$ & $3.89 \pm 0.18 a b$ & 2.73 & $30.8 \pm 1.25 a b$ & 21.6 & $44.0 \pm 2.57 a$ & 30.8 & $64.2 \pm 5.87 a b$ & 44.8 \\
\hline & $\mathrm{B} 40$ & $130 \pm 2.0 b$ & $3.35 \pm 0.19 b$ & 2.58 & $28.4 \pm 1.18 b$ & 21.9 & $38.4 \pm 2.10 b$ & 29.6 & $59.5 \pm 3.15 b$ & 45.9 \\
\hline \multirow[t]{4}{*}{2019} & BO & $118 \pm 6.0 b$ & $3.00 \pm 0.18 b$ & 2.55 & $25.9 \pm 0.83 b$ & 22.0 & $35.0 \pm 2.96 b$ & 29.7 & $54.0 \pm 3.68 b$ & 45.8 \\
\hline & $\mathrm{B} 10$ & $146 \pm 2.2 \mathrm{a}$ & $3.90 \pm 0.26 a$ & 2.67 & $30.5 \pm 1.87 a$ & 20.9 & $43.5 \pm 1.17 a$ & 29.8 & $68.2 \pm 2.65 a$ & 46.7 \\
\hline & $\mathrm{B} 20$ & $142 \pm 8.4 a$ & $3.75 \pm 0.28 a$ & 2.65 & $30.0 \pm 2.07 a b$ & 21.1 & $43.2 \pm 2.78 a$ & 30.4 & $65.1 \pm 3.79 a$ & 45.8 \\
\hline & $\mathrm{B} 40$ & $129 \pm 3.5 b$ & $3.46 \pm 0.10 a b$ & 2.69 & $28.0 \pm 1.90 \mathrm{ab}$ & 21.8 & $38.8 \pm 3.70 \mathrm{ab}$ & 30.0 & $58.7 \pm 1.28 \mathrm{ab}$ & 45.6 \\
\hline \multicolumn{11}{|c|}{ ANOVA } \\
\hline Y & & ns & ns & & $\mathrm{ns}$ & & $\mathrm{ns}$ & & ns & \\
\hline$B$ & & $\star \star$ & $\star \star$ & & $\star \star *$ & & $\star *$ & & ** & \\
\hline$Y \times B$ & & ns & ns & & ns & & $\mathrm{ns}$ & & ns & \\
\hline
\end{tabular}

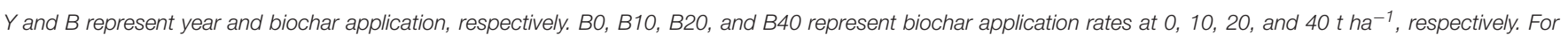

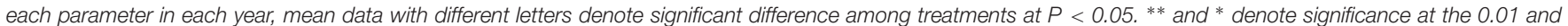
0.05 probability levels, respectively. ns denotes non-significance.

TABLE 4 | Yield and yield components of peanut applied with four rates of biochar in the 2018 and 2019 growing seasons.

\begin{tabular}{|c|c|c|c|c|c|c|}
\hline Year & Treatment & Yield ( $\left.\mathrm{tha}^{-1}\right)$ & Kernel yield (t ha-1) & 100-pod weight (g) & 100-kernel weight (g) & Shelling percentage (\%) \\
\hline \multirow[t]{4}{*}{2018} & $\mathrm{BO}$ & $5.68 \pm 0.17 b$ & $3.91 \pm 0.14 b$ & $198 \pm 7.8 \mathrm{a}$ & $86 \pm 3.0 a$ & $68.8 \pm 0.91 b$ \\
\hline & B10 & $6.51 \pm 0.14 a$ & $4.70 \pm 0.13 a$ & $200 \pm 6.4 a$ & $87 \pm 2.7 a$ & $72.3 \pm 0.62 a$ \\
\hline & B20 & $6.29 \pm 0.19 a$ & $4.30 \pm 0.17 a b$ & $196 \pm 3.7 a$ & $86 \pm 2.7 a$ & $68.4 \pm 0.58 b$ \\
\hline & B40 & $5.69 \pm 0.18 b$ & $3.95 \pm 0.15 b$ & $194 \pm 8.1 \mathrm{a}$ & $85 \pm 1.5 a$ & $69.4 \pm 0.72 b$ \\
\hline \multirow[t]{4}{*}{2019} & $\mathrm{BO}$ & $5.48 \pm 0.22 b$ & $3.76 \pm 0.15 b c$ & $187 \pm 5.2 \mathrm{a}$ & $78 \pm 2.4 a$ & $68.6 \pm 0.35 a b$ \\
\hline & B10 & $6.23 \pm 0.10 a$ & $4.30 \pm 0.13 a$ & $190 \pm 10.1 a$ & $80 \pm 2.8 a$ & $69.1 \pm 1.00 \mathrm{a}$ \\
\hline & $\mathrm{B} 20$ & $6.10 \pm 0.10 a$ & $4.06 \pm 0.11 \mathrm{ab}$ & $190 \pm 10.6 a$ & $82 \pm 3.7 a$ & $66.6 \pm 0.92 \mathrm{bc}$ \\
\hline & B40 & $5.49 \pm 0.17 b$ & $3.60 \pm 0.12 c$ & $179 \pm 7.5 a$ & $77 \pm 5.6 a$ & $65.6 \pm 0.65 c$ \\
\hline \multirow[t]{3}{*}{ ANOVA } & Y & * & ** & ns & ns & $\star \star$ \\
\hline & $\mathrm{B}$ & ** & ** & ns & ns & ** \\
\hline & $\mathrm{Y} \times \mathrm{B}$ & ns & ns & ns & ns & * \\
\hline
\end{tabular}

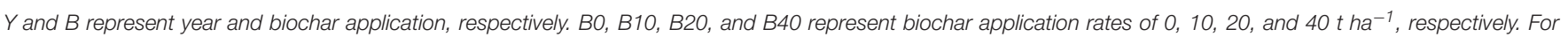

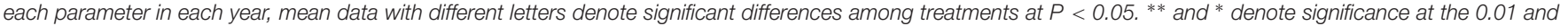
0.05 probability levels, respectively. ns denotes non-significance.

2019, relative to B0. Compared with B0, B10 improved pod nitrogen accumulation $27.0 \%$ in 2018. B10 and B20 improved pod nitrogen accumulation by $26.3 \%$ and $20.6 \%$ in 2019 , as compared to B0.

\section{Yield and Yield Components}

Peanut yield, kernel yield and shelling percentage were significantly affected by year and biochar application (Table 4). There was a significant $\mathrm{Y} \times \mathrm{B}$ interaction for shelling percentage, but not for peanut yield or kernel yield. B10 and B20 increased peanut yield by 14.6 and $10.7 \%$ in $2018,13.7$ and $11.3 \%$ in 2019 , respectively, relative to $\mathrm{B} 0$. B10 increased kernel yield by $20.2 \%$ in 2018 and 14.4\% in 2019, relative to B0. B10 and B20 had similar shelling percentages to $\mathrm{B} 0$, while $\mathrm{B} 40$ had $4.4 \%$ lower shelling percentage than $\mathrm{B} 0$. Among the four biochar treatments, B10 had the highest peanut yield in both years. No significant differences occurred between years, biochar application, or $\mathrm{Y} \times \mathrm{B}$ interaction for 100-pod weight or 100-kernel weight.

\section{Relationship Between Net Photosynthetic Rate, Leaf Nitrogen Content, and Peanut Yield}

The regression analysis indicated that $\mathrm{P}_{n}$ had a significant linear correlation with plant nitrogen accumulation at flowering and pod set in 2018 and 2019 (Figures 4A,B). Plant nitrogen accumulation explained 57.1 and $59.5 \%$ of the variation in $\mathrm{P}_{n}$ at flowering and pod set in 2018, and 60.2 and $70.3 \%$ in 2019, respectively. Positive correlations occurred between $\mathrm{P}_{n}$ at flower and pod set and peanut yield in both years (Figures 4C,D), explaining 74.3 and $86.7 \%$ of the variation in peanut yield in 2018 , and 71.5 and $85.3 \%$ in 2019 , respectively.

\section{PCA Analysis for Yield and Photosynthetic Traits of Peanut}

The PCA results show that PC1 and PC2 explain $95.9 \%$ of the variation in functional traits (Table 5). PC1 explains $83.6 \%$ of 


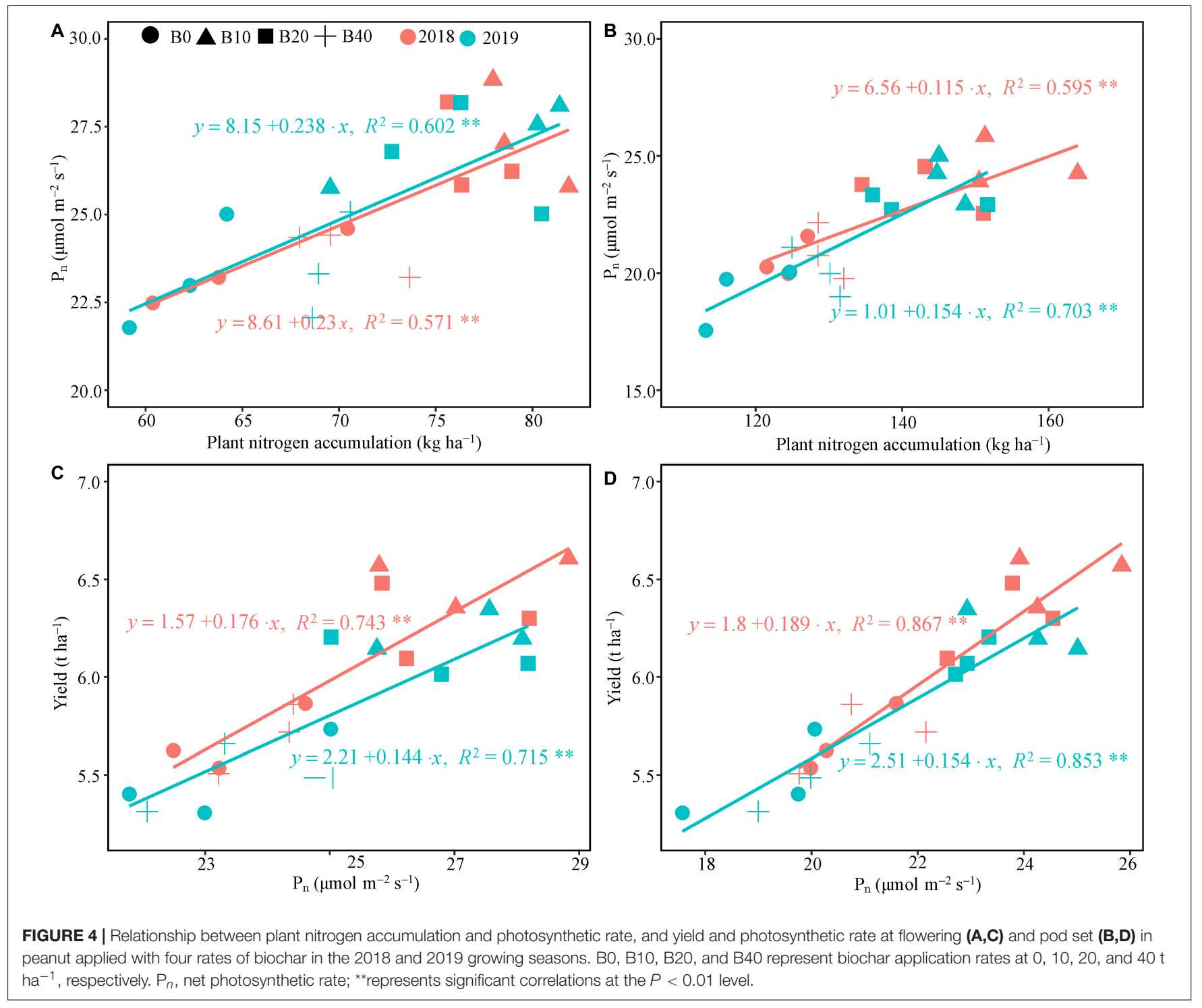

the variability, and accounted mainly for chlorophyll fluorescence parameters $\left(\mathrm{F}_{v} / \mathrm{F}_{m}, \Phi_{P S I I}, \Phi_{N P Q}, \Phi_{N O}, \mathrm{qP}\right.$, and NPQ), gas exchange parameters $\left(\mathrm{P}_{n}, \mathrm{~T}_{r}, \mathrm{G}_{s}, \mathrm{~L}_{s}\right.$, and WUE), LNC, plant nitrogen accumulation and yield and yield components (kernel yield, 100-pod weight, and 100-kernel weight; Figure 5). PC2 explains $12.3 \%$ of the variability and accounts for shelling percentage. The loadings for $\mathrm{qP}, \Phi_{P S I I}$, gas exchange parameters, LNC, plant nitrogen accumulation, yield, and yield components are in quadrant I and IV, and $\Phi_{N P Q}, \Phi_{N O}$, and NPQ are in quadrants II and III, and $\Phi_{N P Q}, \Phi_{N O}$, and NPQ represent limitations in photosynthetic capacity. $\Phi_{P S I}, \Phi_{N P Q}$, and $\Phi_{N O}$ are distributed in different quadrants, indicating compensation effects of photochemical efficiency for dissipation by regulated and non-regulated energy losses. B10 and B20 are located in quadrants I and IV, which have a significant effect on peanut productivity, while B40 and B0 are in quadrant II and III, where absorbed light energy is lost by heat dissipation. The loading arrow of B10 is longer than that of B20. Thus, B10 in quadrant
IV is an appropriate biochar application rate for relatively high photosynthetic capacity and peanut productivity.

\section{DISCUSSION}

\section{Effect of Biochar on Gas Exchange Parameters of Peanut}

Peanut is a C3 crop with high potential for photosynthetic capacity. Therefore, exploring the photosynthetic capacity of peanut is an effective method for improving its productivity (Zelitch, 1982). Some studies have shown that biochar might improve the photosynthetic capacity of crop leaves (Rehman et al., 2016, 2019; Abbas et al., 2017). Biochar application improved leaf photosynthetic rate, which was due to the amelioration of soil physicochemical properties that ultimately increased nitrogen accumulation, and consequently enhanced photosynthetic rate (Liu et al., 2018; Huang et al., 2019; He 
TABLE 5 | Variable loading scores of 18 parameters for four biochar application rate and the proportion of variation of each principal component.

\begin{tabular}{|c|c|c|}
\hline Traits & PC1 & PC2 \\
\hline \multicolumn{3}{|c|}{ Chlorophyll fluorescence parameters } \\
\hline $\mathrm{F}_{v} / \mathrm{F}_{m}$ & 0.95 & -0.26 \\
\hline$\Phi_{P S / l}$ & 0.99 & -0.02 \\
\hline$\Phi_{N P Q}$ & -0.97 & -0.17 \\
\hline$\Phi_{N O}$ & -0.81 & 0.56 \\
\hline $\mathrm{qP}$ & 0.82 & 0.52 \\
\hline NPQ & -0.90 & -0.38 \\
\hline \multicolumn{3}{|c|}{$\begin{array}{l}\text { Gas exchange parameters, leaf nitrogen content and plant } \\
\text { nitrogen accumulation }\end{array}$} \\
\hline$P_{n}$ & 0.99 & 0.06 \\
\hline $\mathrm{T}_{r}$ & 0.99 & 0.03 \\
\hline $\mathrm{G}_{S}$ & 0.98 & 0.15 \\
\hline$L_{s}$ & 0.99 & 0.04 \\
\hline WUE & 0.99 & 0.13 \\
\hline Leaf nitrogen content & 0.82 & 0.51 \\
\hline Plant nitrogen accumulation & 0.97 & 0.22 \\
\hline \multicolumn{3}{|l|}{ Yield and yield components } \\
\hline Yield & 0.99 & -0.01 \\
\hline Kernel yield & 0.97 & -0.19 \\
\hline 100-pod weight & 0.70 & -0.64 \\
\hline 100-kernel weight & 0.86 & -0.30 \\
\hline Shelling percentage & 0.54 & -0.66 \\
\hline Eigenvalue & 15.1 & 2.2 \\
\hline Variance (\%) & 83.6 & 12.3 \\
\hline Cumulative variance (\%) & 83.6 & 95.9 \\
\hline \multicolumn{3}{|c|}{$\begin{array}{l}F_{v} / F_{m} \text {, maximal efficiency of PSII photochemistry after dark adaptation; } \Phi_{P S I I} \\
\text { actual efficiency of PSIl photochemistry after light adaptation; } \Phi_{N P Q} \text {, quantum } \\
\text { yield for energy dissipated via } \Delta \mathrm{pH} \text { and xanthophyll-regulated processes; } \Phi_{N O} \text {, } \\
\text { The quantum yield of non-regulated energy loss in PSII; qP, photochemical } \\
\text { quenching; NPQ, non-photochemical quenching; } P_{n} \text {, net photosynthetic rate; } T_{r} \text {, } \\
\text { transpiration rate; } G_{S} \text {, stomatal conductance; } L_{S} \text {, stomatal limitation; and WUE, } \\
\text { water use efficiency. For each parameter, the largest variable loading scores in the } \\
\text { two components are in bold. }\end{array}$} \\
\hline
\end{tabular}

et al., 2020). In our study, $\mathrm{B} 10$ enhanced $\mathrm{P}_{n}, \mathrm{~T}_{r}, \mathrm{G}_{s}, \mathrm{~L}_{s}$, and WUE at critical periods of peanut growth. In contrast, $40 \mathrm{tha}^{-1}$ biochar decreased these parameters, relative to $10 \mathrm{t} \mathrm{ha}^{-1}$ biochar (Figure 3), indicating that more biochar is not always beneficial for leaf photosynthesis. Differences in $\mathrm{P}_{n}$ among the four biochar rates could be due to the positive correlation between nitrogen accumulation and $\mathrm{P}_{n}$ at flowering and pod set in both years, as biochar application increased plant nitrogen accumulation. Plant nitrogen accumulation was higher in B10 and B20, but decreased in B40 at flowering and pod set (Tables 2, 3). The highest rate of biochar $\left(40 \mathrm{t} \mathrm{ha}^{-1}\right)$ may limit plant nitrogen accumulation which decreased leaf photosynthesis, which was likely attributed to nitrogen immobilization caused by the high $\mathrm{C} / \mathrm{N}$ ratio (Asai et al., 2009). Photosynthetic rate had a positive relationship with LNC (Evans, 1989). In this study, B10 improved LNC at flowering (vegetative growth) by up to $6.6 \%$. The significant increase in LNC at pod set was modest and may be due to reduction at pod set (reproductive growth), with more nitrogen transformed to pod (Tables 2, 3). Furthermore, the increase in dry matter production may have decreased leaf nitrogen due to

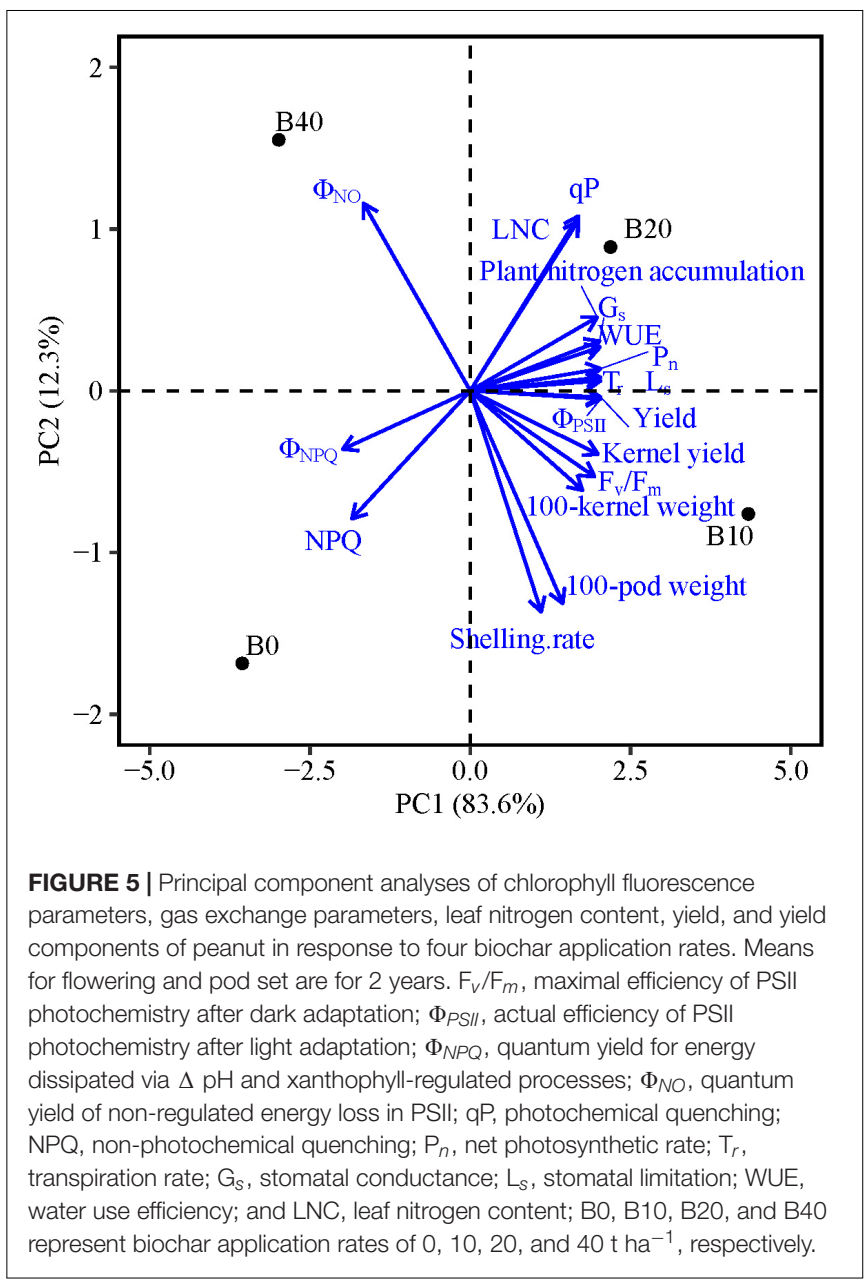

the dilution effect (Guo et al., 2021). This enhancement of leaf photosynthetic rate could be explained by increased $\mathrm{G}_{s}$ and $\mathrm{T}_{r}$ after biochar application (Figure 3). The improving $\mathrm{G}_{s}$ and $\mathrm{T}_{r}$ may be associated with the increased soil water holding capacity, which might be resulting from the porous physical structure of biochar (Laghari et al., 2015; He et al., 2020). Additionally, some evidences suggested that biochar benefited root morphological development, including increased root volume, surface area and root density, to acquire more nutrients and water for enhancing photosynthesis (Bruun et al., 2014; Xiang et al., 2017). In fact, our study observed that $10 \mathrm{t} \mathrm{ha}^{-1}$ biochar promoted root morphology of peanut (Xia et al., 2021b). Hence, $10 \mathrm{t} \mathrm{ha}^{-1}$ biochar improved the nitrogen accumulation and photosynthetic rate, and consequently peanut yield.

\section{Effect of Biochar on Chlorophyll Fluorescence Parameters of Peanut}

Chlorophyll fluorescence is an important photosynthetic parameter that reflects the absorption and utilization of light energy in PSII. $\mathrm{F}_{v} / \mathrm{F}_{m}$ represents the conversion efficiency of primary light energy in the PSII reaction center. Decreases in $\mathrm{F}_{v} / \mathrm{F}_{m}$ are often observed when plants are exposed to abiotic and biotic stresses in the light (Baker, 2008). In our study, $\mathrm{F}_{v} / \mathrm{F}_{m}$ did 
not significantly differ between treatments at flowering and pod set in either year (Figures 2A,G), which is consistent with Marks et al. (2016). $\Phi_{P S I}$ is an indicator of the electron transport rate in leaves, and higher $\Phi_{P S I}$ indicates a higher capacity of leaves to convert photon energy into chemical energy (Li et al., 2010). $\Phi_{N P Q}$ is an important indicator of photo-protection energy dissipation, and higher $\Phi_{N P Q}$ value shows a higher capacity to eliminate redundancy light energy by regulatory heat dissipation mechanism. $\Phi_{N O}$ is the combined pathway of radiative and non-radiative deexcitation reactions, and higher $\Phi_{N O}$ indicates that the absorbed light energy cannot be consumed completely through photochemical energy conversion and protective regulation mechanisms (Kramer et al., 2004; Klughammer and Schreiber, 2008; Chen et al., 2017). In this study, no significant difference in $\Phi_{N O}$ occurred between treatments at flowering or pod set in either year (Figures 2D,J). In terms of energy distribution, B10 promoted photosynthetic activity in peanut leaves, significantly increasing $\Phi_{P S I I}$, and decreasing $\Phi_{N P Q}$ and $\Phi_{N O}$ at flowering and pod set in both years (Figure 2). B0 and B40 decreased $\Phi_{P S I}$ and increased $\Phi_{N P Q}$, indicating that an increase in regulated heat dissipation could protect the photosynthetic apparatus. $\mathrm{qP}$ represents the proportion of open PSII reaction centers (Hazrati et al., 2016). NPQ mainly comprises regulated and non-regulated energy dissipation and indicates that the light energy absorbed by PSII antenna pigments cannot be used for photochemical electron transfer, which dissipates as heat (Long et al., 2013; Perkins et al., 2018). Tang et al. (2020) reported that biochar pyrolyzed at $600^{\circ} \mathrm{C}$ increased $\mathrm{qP}$ and decreased NPQ, relative to the no-biochar treatment. Our results showed that B10 and B20 improved $\mathrm{qP}$ at flowering and pod set, and reduced NPQ at pod set in both years (Figure 2). It shown that 10 and $20 \mathrm{t} \mathrm{ha}^{-1}$ biochar enhanced the proportion of open PSII reaction centers and photosynthetic electron transfer rates in peanut leaves and reduced heat dissipation, which enable full use of the light energy absorbed in leaves for photosynthesis, and increased peanut yield. Our results are in agreement with those of Ali et al. (2020), who reported that appropriate rate of biochar increased $\mathrm{qP}$ and decreased NPQ at maturity stage. Biochar application improved nitrogen uptake from the soil (Sadaf et al., 2017), and a higher nitrogen concentration increased $\Phi_{P S I I}, \mathrm{qP}$ and decreased NPQ (Lin et al., 2013). Additionally, it's probably because biochar application enhanced leaf chlorophyll content (Feng et al., 2021), which ensured the synthesis of various enzymes and electron transporter in photosynthetic carbon assimilation, and consequently ameliorate photosynthetic function in leaves (Hou et al., 2021). Thus, the light energy absorbed by leaf was more used in photochemical processes, which led to the increase of $\mathrm{qP}$ and decrease of NPQ. In Summary, these results confirmed the potential of biochar for improving chlorophyll fluorescence traits. The internal mechanisms for biochar improving chlorophyll fluorescence traits merit further investigation.

\section{Effect of Biochar on Peanut Yield}

Significant differences of pod yield were observed at least 20$40 \mathrm{t} \mathrm{ha} \mathrm{h}^{-1}$ biochar application in pot experiment ( $\mathrm{Xu}$ et al., 2015). In our study, $10 \mathrm{tha}^{-1}$ biochar produced the maximum peanut yield (and kernel yield and shelling percentage; Table 4), as reported by Ye et al. (2019). Yamato et al. (2006) reported that $10 \mathrm{t} \mathrm{ha}^{-1}$ biochar application combined with fertilizer in infertile soil increased peanut yield by 50\%. Similarly, the biochar application rate of $10 \mathrm{t} \mathrm{ha}^{-1}$ significantly increased peanut pod yield by $23 \%$ compared to the inorganic fertilizer only treatment (Agegnehu et al., 2015). In another study, rice husk and cottonseed husk biochar applications at $50 \mathrm{t}$ $\mathrm{ha}^{-1}$ increased peanut yields by 16.8 and $14.4 \%$, respectively, relative to the no-biochar amendment treatment (Tan et al., 2018). In this study, B40 decreased peanut yield, relative to B10 (Table 4). Some studies have reported that high rates of biochar can cause nitrogen immobilization and decrease nitrogen accumulation due to the high $\mathrm{C} / \mathrm{N}$ ratio, reducing yield (Lehmann et al., 2002; Asai et al., 2009; Li et al., 2018; Yan et al., 2019). Despite the variation between studies, legumes generally respond better to biochar than other crops. For example, biochar application increased the yields of legumes, wheat, maize, and rice by about $30,11,8$, and $7 \%$, respectively, Liu et al. (2013). Biochar has strong potential to improve crop productivity, especially in drought and poor soils (Batool et al., 2015; Haider et al., 2017; Hussain et al., 2017). The large interannual variability in rainfall is the main climatic factor during pod formation period, causing fluctuations in peanut yield (Craufurd et al., 2006). High soil moisture content is conducive to pod filling in peanut. In our study, August 2019 had more rainfall than August 2018 (Figure 1), and the peanut yields differed accordingly.

The pod setting stage is critical for peanut yield formation. In our study, B10 significantly improved the photosynthetic capacity of peanut at pod set (Figure 4), ensuring reproductive growth during the critical growth period and increasing peanut yield. The regression coefficient between $\mathrm{P}_{n}$ and peanut yield was higher at pod set than at flowering in both years (Figure 4), indicating that photosynthetic capacity at pod set had a positive effect on yield. Overall, the increased yield at $10 \mathrm{t} \mathrm{ha}^{-1}$ biochar might be due to an enhanced photosynthetic capacity of functional leaves (Figure 5).

\section{CONCLUSION}

Biochar application had a significant positive effect on photosynthetic capacity and yield in peanut. Maximum photochemical efficiency, actual photochemical efficiency, photochemical quenching, gas exchange parameters, leaf nitrogen content, plant nitrogen accumulation, yield, and yield components of peanut with increasing biochar application rate to $10 \mathrm{t} \mathrm{ha}^{-1}$ (B10). B10 significantly enhanced $\Phi_{P S I I}$ and $\mathrm{qP}$ in functional leaves of peanut due to the transfer of more absorbed energy to photochemical reactions, ensuring a higher photosynthetic capacity at flowering and pod set and higher peanut yield than the other biochar rates. These results are in agreement with our hypothesis. Therefore, $10 \mathrm{t} \mathrm{ha}^{-1}$ biochar is recommended for increasing peanut yield in Northwest Liaoning, China. The results from this study enhances our understanding of the effects of biochar application on peanut photosynthesis and yield. 


\section{DATA AVAILABILITY STATEMENT}

The original contributions presented in the study are included in the article/supplementary material, further inquiries can be directed to the corresponding author/s.

\section{AUTHOR CONTRIBUTIONS}

GX, TW, DC, and TC designed the experiment. SW, YW, and QY conducted the experiments, collected and analyzed the

\section{REFERENCES}

Abbas, T., Rizwan, M., Ali, S., Adrees, M., Zia-ur-Rehman, M., Qayyum, M. F., et al. (2017). Effect of biochar on alleviation of cadmium toxicity in wheat (Triticum aestivum L.) grown on Cd-contaminated saline soil. Environ. Sci. Pollut. Res. 25, 25668-25680. doi: 10.1007/s11356-017-8987-4

Abideen, Z., Koyro, H. W., Huchzermeyer, B., Gul, B., and Khan, M. A. (2020). Impact of a biochar or a biochar-compost mixture on water relation, nutrient uptake and photosynthesis of Phragmites karka. Pedosphere 30, 466-477. doi: 10.1016/S1002-0160(17)60362-X

Agegnehu, G., Bass, A. M., Nelson, P. N., Muirhead, B., Wright, G., and Bird, M. I. (2015). Biochar and biochar-compost as soil amendments: effects on peanut yield, soil properties and greenhouse gas emissions in tropical North Queensland, Australia. Agric. Ecosys. Environ. 213, 72-85. doi: 10.1016/j.agee. 2015.07.027

Ali, I., Ullah, S., He, L., Zhao, Q., Iqbal, A., Wei, S. Q., et al. (2020). Combined application of biochar and nitrogen fertilizer improves rice yield, microbial activity and N-metabolism in a pot experiment. Peer J. 8:e10311. doi: 10.7717/ peerj. 10311

Ali, S., Xu, Y., Jia, Q., Ma, X., Ahmad, I., Adnan, M., et al. (2018). Interactive effects of plastic film mulching with supplemental irrigation on winter wheat photosynthesis, chlorophyll fluorescence and yield under simulated precipitation conditions. Agri. Water Manag. 207, 1-14. doi: 10.1016/j.agwat. 2018.05.013

Asai, H., Samson, B. K., Stephan, H. M., Songyikhangsuthor, K., Homma, K., Kiyono, Y., et al. (2009). Biochar amendment techniques for upland rice production in Northern Laos 1. Soil physical properties, leaf SPAD and grain yield. Field Crops Res. 111, 81-84. doi: 10.1016/j.fcr.2008.10.008

Bai, W., Sun, Z., Zheng, J., Hou, Z., Liu, Y., Feng, L., et al. (2014). Effect of different planting patterns on maize growth and yield in western Liaoning province. Acta Agron. Sinica. 40, 181-189. doi: 10.3724/SP.J.1006.2014.00181

Baker, N. R. (2008). Chlorophyll fluorescence: a probe of photosynthesis in vivo. Ann. Rev. Plant Biol. 59, 89-113. doi: 10.1146/annurev.arplant.59.032607. 092759

Batool, A., Taj, S., Rashid, A., Khalid, A., Qadeer, S., Saleem, A. R., et al. (2015). Potential of soil amendments (biochar and gypsum) in increasing water use efficiency of Abelmoschus esculentus L. Moench. Front. Plant Sci. 6:733. doi: 10.3389/fpls.2015.00733

Bruun, E. W., Petersen, C. T., Hansen, E., Holm, J. K., and Hauggaard-Nielsen, H. (2014). Biochar amendment to coarse sandy subsoil improves root growth and increases water retention. Soil Use Manage. 30, 109-118. doi: 10.1111/sum. 12102

Chen, Y. S., Wang, Z. J., Shen, Z. J., Ou, Z. L., Xu, D. C., Yuan, Z. X., et al. (2017). Effects of oxytetracycline on growth and chlorophyll fluorescence in rape (Brassica campestris L.). Pol. J. Environ. Stud. 26, 995-1001. doi: 10.15244/ pjoes $/ 67575$

Clough, T. J., Condron, L. M., Kammann, C., and Muller, C. (2013). A review of biochar and soil nitrogen dynamics. Agronomy 3, 275-293. doi: 10.3390/ agronomy3020275

Craufurd, P. Q., Prasad, P. V. V., Waliyar, F., and Taheri, A. (2006). Drought, pod yield, pre-harvest Aspergillus infection and aflatoxin contamination on peanut in Niger. Field Crops Res. 98, 20-29. doi: 10.1016/j.fcr.2005.12.001 data, and prepared the manuscript. JZ, YC, and KS revised the manuscript. All authors contributed to the article and approved the submitted version.

\section{FUNDING}

This research was funded by the Natural Science Foundation of Liaoning Province (Project No. 20180550819) and Scientific Research Fund of Liaoning Provincial Education Department (Project No. LSNJC202003).

El-Naggar, A., Lee, S. S., Rinklebe, J., Farooq, M., Song, H., Sarmah, A. K., et al. (2019). Biochar application to low fertility soils: a review of current status, and future prospects. Geoderma 337, 536-554. doi: 10.1016/j.geoderma.2018.09.034

Evans, J. R. (1989). Photosynthesis and nitrogen relationships in leaves of C3 plants. Oecologia 78, 9-19. doi: 10.1007/bf0037 7192

Fang, X., Li, Y., Nie, J., Wang, C., Huang, K., Zhang, Y. K., et al. (2018). Effects of nitrogen fertilizer and planting density on the leaf photosynthetic characteristics, agronomic traits and grain yield in common buckwheat (Fagopyrum esculentum M.). Field Crops Res. 219, 160-168. doi: 10.1016/j.fcr. 2018.02.001

FAOSTAT (2018). Food Agriculture and Organization of the United Nations (FAO). Available online at: http://www.fao.org/faostat/en/\#data/QC (accessed 8 Aug, 2020).

Feng, W. Y., Yang, F., Cen, R., Liu, J., Qu, Z. Y., Miao, Q. F., et al. (2021). Effects of straw biochar application on soil temperature, available nitrogen and growth of corn. J. Environ. Manage. 277:111331. doi: 10.1016/j.jenvman.2020.111331

Guo, L. L., Bornø, M. L., Niu, W. Q., and Liu, F. L. (2021). Biochar amendment improves shoot biomass of tomato seedlings and sustains water relations and leaf gas exchange rates under different irrigation and nitrogen regimes. Agri. Water Manag. 245:106580. doi: 10.1016/j.agwat.2020.106580

Haider, G., Steffens, D., Moser, G., Müller, C., and Kammann, C. I. (2017). Biochar reduced nitrate leaching and improved soil moisture content without yield improvements in a four-year field study. Agric. Ecosyst. Environ. 237, 80-94. doi: 10.1016/j.agee.2016.12.019

Hazrati, S., Tahmasebi, S. Z., Modarres, S. S. A. M., Mokhtassi, B. A., and Nicola, S. (2016). Effects of water stress and light intensity on chlorophyll fluorescence parameters and pigments of Aloe vera L. Plant Physiol. Biochem. 106, 141-148. doi: 10.1016/j.plaphy.2016.04.046

He, Y. H., Yao, Y. X., Ji, Y. H., Deng, J., Zhou, G. Y., Liu, R. Q., et al. (2020). Biochar amendment boosts photosynthesis and biomass in $\mathrm{C} 3$ but not $\mathrm{C} 4$ plants: a global synthesis. GCB Bioenergy 12, 605-617. doi: 10.1111/gcbb.12720

Hou, W. H., Zhang, Y. X., Wang, H. J., Zhang, Q. X., Hou, M. L., Cong, B. M., et al. (2021). Effects of nitrogen application level on leaf photosynthetic characteristics and chlorophyll fluorescence characteristics of Leymus chinensis. Acta Agrestia Sinica 29, 532-536. doi: 10.11733/j.issn.1007-0435.2021.03.014

Huang, X. F., Li, S. Q., Li, S. Y., Ye, G. Y., Lu, L. J., Zhang, L., et al. (2019). The effects of biochar and dredged sediments on soil structure and fertility promote the growth, photosynthetic and rhizosphere microbial diversity of Phragmites communis (Cav.) Trin. ex Steud. Sci. Total Environ. 697:134073. doi: 10.1016/j.scitotenv.2019.134073

Hussain, M., Farooq, M., Nawaz, A., Al-Sadi, A. M., Solaiman, Z. M., Alghamdi, S. S., et al. (2017). Biochar for crop production: potential benefits and risks. J. Soil Sediment. 17, 685-716. doi: 10.1007/s11368-016-1360-2

Ippolito, J. A., Cui, L. Q., Kammann, C., Mönnig, N. W., Estavillo, J. M., Mendizabal, T. F., et al. (2020). Feedstock choice, pyrolysis temperature and type influence biochar characteristics: a comprehensive meta-data analysis review. Biochar 2, 421-438. doi: 10.1007/s42773-020-00067-x

Kammann, C. I., Linsel, S., Gößling, J. W., and Koyro, H. W. (2011). Influence of biochar on drought tolerance of Chenopodium quinoa Willd and on soil-plant relations. Plant Soil 345, 195-210. doi: 10.1007/s11104-0110771-5 
Kassambara, A. (2015). Factoextra: Visualization of the Outputs of a Multivariate Analysis. R Package Version 1: Statistical Tools for Highthroughput Data Analysis. Available online at: http://www.sthda.com

Klughammer, C., and Schreiber, U. (2008). Complementary PS II quantum yields calculated from simple fluorescence parameters measured by PAM fluorometry and the saturation pulse method. PAM Appl. Notes 1, 27-35.

Kooten, O. V., and Snel, J. F. H. (1990). The use of chlorophyll fluorescence nomenclature in plant stress physiology. Photosynth. Res. 25, 147-150. doi: 10.1007/BF00033156

Kramer, D. M., Johnson, G., Kiirats, O., and Edwards, G. E. (2004). New fluorescence parameters for the determination of QA redox state and excitation energy fluxes. Photosynth. Res. 79, 209-218. doi: 10.1023/B:PRES.0000015391. 99477.0d

Laghari, M., Mirjat, M. S., Hu, Z., Fazal, S., Xiao, B., Hu, M., et al. (2015). Effects of biochar application rate on sandy desert soil properties and sorghum growth. Catena 135, 313-320. doi: 10.1016/j.catena.2015.08.013

Lehmann, J., da Silva, J. P. Jr., Steiner, C., Nehls, T., Zech, W., and Glaser, B. (2002). Nutrient availability and leaching in an archaeological Anthrosol and a Ferralsol of the Central Amazon basin: fertilizer, manure and charcoal amendments. Plant Soil 249, 343-357. doi: 10.1023/A:1022833116184

Lehmann, J., Rillig, M. C., Thies, J., Masiello, C. A., Hockaday, W. C., and Crowley, D. (2011). Biochar effects on soil biota-a review. Soil Biol. Biochem. 43, 1812-1836. doi: 10.1016/j.soilbio.2011.04.022

Leng, L. J., Xu, S. Y., Liu, R. F., Yu, T., Zhou, X. M., Leng, S. Q., et al. (2020). Nitrogen containing functional groups of biochar: an overview. Bioresour. Technol. 298:122286. doi: 10.1016/j.biortech.2019.122286

Li, G., Wan, S., Zhou, J., Yang, Z., and Qin, P. (2010). Leaf chlorophyll fluorescence, hyperspectral reflectance, pigments content, malondialdehyde and proline accumulation responses of castor bean (Ricinus communis L.) seedlings to salt stress levels. Ind. Crops Prod. 31, 13-19. doi: 10.1016/j.indcrop.2009.07.015

Li, S. L., Zhou, P., and Shang, G. (2018). Positive effects of apple branch biochar on wheat yield only appear at a low application rate, regardless of nitrogen and water conditions. J. Soil Sediment. 18, 3235-3243. doi: 10.1007/s11368-0181994-3

Li, X. Y., and Gong, J. D. (2002). Effects of different ridge: furrow ratios and supplemental irrigation on crop production in ridge and furrow rainfall harvesting system with mulches. Agri Water Manag. 54, 243-254. doi: 10.1016/ S0378-3774(01)00172-X

Li, Y. S., Wu, L. H., Zhao, L. M., Lu, X. H., Fan, Q. L., and Zhang, F. S. (2007). Influence of continuous plastic film mulching on yield, water use efficiency and soil properties of rice fields under nonflooding condition. Soil Tillage Res. 93, 370-378. doi: 10.1016/j.still.2006.05.010

Lin, Y. C., Hu, Y. G., Ren, C. Z., Guo, L. C., Wang, C. L., Jiang, Y., et al. (2013). Effects of nitrogen application on chlorophyll fluorescence parameters and leaf gas exchange in naked oat. J. Integr. Agric. 12, 2164-2171. doi: 10.1016/S20953119(13)60346-9

Lin, Z., Liu, Q., Liu, G., Cowie, A. L., Bei, Q., Liu, B. I. U., et al. (2017). Effects of different biochars on Pinus elliottii growth, $\mathrm{N}$ use efficiency, soil $\mathrm{N} 2 \mathrm{O}$ and $\mathrm{CH} 4$ emissions and C storage in a subtropical area of China. Pedosphere 27, 248-261. doi: 10.1016/S1002-0160(17)60314-X

Liu, Q., Zhang, Y. H., Liu, B. J., Amonette, J. E., Lin, Z. B., Liu, G., et al. (2018). How does biochar influence soil N cycle? A meta-analysis. Plant Soil 426, 211-225. doi: 10.1007/s11104-018-3619-4

Liu, X. Y., Zhang, A. F., Ji, C. Y., Joseph, S., Bian, R. J., Li, L. Q., et al. (2013). Biochar's effect on crop productivity and the dependence on experimental conditions-a meta-analysis of literature data. Plant Soil 373, 583-594. doi: 10.1007/s11104-013-1806-X

Liu, Z. X., Gao, F., Yang, J. Q., Zhen, X. Y., Li, Y., Zhao, J. H., et al. (2019). Photosynthetic characteristics and uptake and translocation of nitrogen in peanut in a wheat-peanut rotation system under different fertilizer management regimes. Front. Plant Sci. 10:86. doi: 10.3389/fpls.2019.000086

Long, J. R., Ma, G. H., Wan, Y. Z., Song, C. F., Sun, J., and Qin, R. J. (2013). Effects of nitrogen fertilizer level on chlorophyll fluorescence characteristics in flag leaf of super hybrid rice at late growth stage. Rice Sci. 20, 220-228. doi: 10.1016/S1672-6308(13)60138-9

Luo, H. Y., Xu, Z. J., Li, Z. D., Li, X. P., Lv, J. W., Ren, X. P., et al. (2017). Development of SSR markers and identification of major quantitative trait loci controlling shelling percentage in cultivated peanut (Arachis hypogaea L.). Theor. Appl. Genet. 130, 1635-1648. doi: 10.1007/s00122-017-2915-3

Marks, E. A. N., Mattana, S., Alcañiz, J. M., Pérez-Herrero, E., and Domene, X. (2016). Gasifier biochar effects on nutrient availability, organic matter mineralization, and soil fauna activity in a multi-year Mediterranean trial. Agric. Ecosyst. Environ. 215, 30-39. doi: 10.1016/j.agee.2015. 09.004

Maxwell, K., and Johnson, G. N. (2000). Chlorophyll fluorescence-a practical guide. J. Exp. Bot. 51, 659-668. doi: 10.1093/jexbot/51.345.659

Nguyen, T. T. N., Wallace, H. M., Xu, C. Y., Xu, Z. H., Farrar, M. B., Joseph, S., et al. (2017). Short-term effects of organo-mineral biochar and organic fertilisers on nitrogen cycling, plant photosynthesis, and nitrogen use efficiency. J. Soil. Sediment. 17, 2763-2774. doi: 10.1007/s11368-017-1839-5

Novak, J. M., Busscher, W. J., Watts, D. W., Amonette, J. E., Ippolito, J. A., Lima, I. M., et al. (2012). Biochars impact on soil-moisture storage in an ultisol and two aridisols. Soil Sci. 177, 310-320. doi: 10.1097/SS.0b013e31824e5593

Peel, M. C., Finlayson, B. L., and McMahon, T. A. (2007). Updated world map of the Köppen Geiger climate classification. Hydrol. Earth Syst. Sci. Discuss. 11, 1633-1644. doi: 10.5194/hess-11-1633-2007

Perkins, R., Williamson, C., Lavaud, J., Mouget, J. L., and Campbell, D. A. (2018). Time-dependent upregulation of electron transport with concomitant induction of regulated excitation dissipation in Haslea diatoms. Photosynth. Res. 137, 377-388. doi: 10.1007/s11120-018-0508-X

Rehman, M., Liu, L. J., Bashir, S., Saleema, M. H., Chen, C., Peng, D. X., et al. (2019). Influence of rice straw biochar on growth, antioxidant capacity and copper uptake in ramie (Boehmeria nivea L.) grown as forage in aged copper contaminated soil. Plant Physiol. Biochem. 138, 121-129. doi: 10.1016/j.plaphy. 2019.02.021

Rehman, M. Z., Rizwan, M., Ali, S., Fatima, N., Yousaf, B., Naeem, A., et al. (2016). Contrasting effects of biochar, compost and farm manure on alleviation of nickel toxicity in maize (Zea mays L.) in relation to plant growth, photosynthesis and metal uptake. Ecotoxicol. Environ. Saf. 133, 218-225. doi: 10.1016/j.ecoenv.2016.07.023

Sadaf, J., Shah, G. A., Shahzad, K., Ali, N., Shahid, M., Ali, S., et al. (2017). Improvements in wheat productivity and soil quality can accomplish by coapplication of biochars and chemical fertilizers. Sci. Total Environ. 607-608, 715-724. doi: 10.1016/j.scitotenv.2017.06.178

Steinmetz, Z., Wollmann, C., Schaefer, M., Buchmann, C., David, J., Tröger, J., et al. (2016). Plastic mulching in agriculture. Trading short-term agronomic benefits for long-term soil degradation? Sci. Total Environ. 550, 690-705. doi: 10.1016/j.scitotenv.2016.01.153

Sun, T., Li, G., Ning, T. Y., Zhang, Z. M., Mi, Q. H., and Lal, R. (2018). Suitability of mulching with biodegradable film to moderate soil temperature and moisture and to increase photosynthesis and yield in peanut. Agri Water Manag. 208, 214-223. doi: 10.1016/j.agwat.2018.06.027

Tan, G. C., Wang, H. Y., Xu, N., Liu, H. B., and Zhai, L. M. (2018). Biochar amendment with fertilizers increases peanut $\mathrm{N}$ uptake, alleviates soil $\mathrm{N} 2 \mathrm{O}$ emissions without affecting $\mathrm{NH} 3$ volatilization in field experiments. Environ. Sci. Pollut. Res. 25, 8817-8826. doi: 10.1007/s11356-017$1116-6$

Tang, J. W., Zhang, S. D., Zhang, X. T., Chen, J. H., He, X. Y., and Zhang, Q. Z. (2020). Effects of pyrolysis temperature on soil-plant-microbe responses to Solidago canadensis L.-derived biochar in coastal salinealkali soil. Sci. Total Environ. 731:138938. doi: 10.1016/j.scitotenv.2020.13 8938

Xia, G. M., Wang, Y. J., Hu, J. Q., Wang, S. J., Zhang, Y., Wu, Q., et al. (2021a). Effects of supplemental irrigation on water and nitrogen use, yield, and kernel quality of peanut under nitrogen-supplied conditions. Agri Water Manag. 243:106518. doi: 10.1016/j.agwat.2020.106518

Xia, G. M., Wang, Y. J., Wang, S. J., Yang, Q. F., and Chi, D. C. (2021b). Effects of irrigation methods and biochar on peanut root, phosphorus utilization and yield. T. Chin. Soc. Agric. Mach.

Xiang, Y. Z., Deng, Q., Duan, H. L., and Guo, Y. (2017). Effects of biochar application on root traits: a meta-analysis. GCB Bioenergy 9, 1563-1572. doi: 10.1111/gcbb.12449

Xu, C. Y., Hosseini, B. S., Hao, Y., Rachaputi, R. C. N., Wang, H., Xu, Z. H., et al. (2015). Effect of biochar amendment on yield and photosynthesis of peanut on 
two types of soils. Environ. Sci. Pollut. Res. 22, 6112-6125. doi: 10.1007/s11356014-3820-9

Yamato, M., Okimori, Y., Wibowo, I. F., Anshori, S., and Ogawa, M. (2006). Effects of the application of charred bark of Acacia mangium on the yield of maize, cowpea and peanut, and soil chemical properties in South Sumatra, Indonesia. Soil Sci. Plant Nutr. 52, 489-495. doi: 10.1111/j.1747-0765.2006.0 0065.X

Yan, Q. Y., Dong, F., Li, J. H., Duan, Z. Q., Yang, F., Li, X., et al. (2019). Effects of maize straw-derived biochar application on soil temperature, water conditions and growth of winter wheat. Eur. J. Soil Sci. 70, 1280-1289. doi: 10.1111/ejss. 12863

Ye, L. L., Camps, A. M., Shen, Q. H., Lehmann, J., Singh, B., and Sabir, M. (2019). Biochar effects on crop yields with and without fertilizer: a meta-analysis of field studies using separate controls. Soil Use Manage. 36, 2-18. doi: 10.1111/ sum. 12546

Ye, Z. X., Liu, L. Y., Tan, Z. X., Zhang, L. M., and Huang, Q. Y. (2020). Effects of pyrolysis conditions on migration and distribution of biochar nitrogen in the soil-plant-atmosphere system. Sci. Total Environ. 723:138006. doi: 10.1016/ j.scitotenv.2020.138006

Zelitch, I. (1982). The close relationship between net photosynthesis and crop yield. BioScience 32, 796-802. doi: 10.2307/130 8973

Conflict of Interest: The authors declare that the research was conducted in the absence of any commercial or financial relationships that could be construed as a potential conflict of interest.

Copyright $\odot 2021$ Wang, Zheng, Wang, Yang, Chen, Chen, Chi, Xia, Siddique and Wang. This is an open-access article distributed under the terms of the Creative Commons Attribution License (CC BY). The use, distribution or reproduction in other forums is permitted, provided the original author(s) and the copyright owner(s) are credited and that the original publication in this journal is cited, in accordance with accepted academic practice. No use, distribution or reproduction is permitted which does not comply with these terms. 